\title{
AVALIAÇÃO AMBIENTAL EM UMA COOPERATIVA DE MATERIAIS RECICLÁVEIS
}

\author{
Nagiélie Muara SILVA ${ }^{1 *}$; Camilla Stheffani Oliveira Machado ${ }^{2}$; Maria Cristina Rizk ${ }^{3}$ \\ 1,2 Discente em Engenharia Ambiental pela Universidade Estadual Paulista - UNESP - Presidente Prudente. * Bolsista \\ PIBIC. ${ }^{3}$ Docente da Universidade Estadual Paulista - UNESP - Presidente Prudente. E-mail: nagieliemuara@gmail.com
}

\section{RESUMO}

A geração de materiais recicláveis é decorrente, principalmente, do consumo e aumenta a cada dia, sendo de suma importância a inserção de cooperativas de reciclagem, com o objetivo de recuperar a qualidade desses materiais que passam então a serem aproveitados. Neste estudo, foi feito um acompanhamento e análise dos aspectos e impactos ambientais de uma cooperativa de materiais recicláveis, visando a proposição de medidas para mitigar os impactos críticos. Os resultados obtidos permitem dizer que a atividade apresenta benefícios sociais e ambientais, gerando empregos para aqueles que antes eram catadores de rua ou de lixões e destinando corretamente os resíduos. Dentre os principais impactos negativos levantados, cita-se a estocagem de resíduos como a maior geradora de impactos críticos, junto com a falta de equipamentos de segurança e a contaminação dos resíduos recicláveis devido à vinda dos materiais sem adequada higienização.

Palavras-chave: Diagnóstico Ambiental; Avaliação de Aspectos e Impactos Ambientais, Cooperativa de Materiais Recicláveis.

\section{1 - INTRODUÇÃO E OBJETIVO}

Um dos maiores desafios com que se defronta a sociedade moderna é o equacionamento da geração excessiva e da disposição final ambientalmente segura dos resíduos sólidos. A preocupação mundial em relação aos resíduos sólidos, em especial os domiciliares, tem aumentado ante o crescimento da produção, do gerenciamento inadequado e da falta de áreas de disposição final (JACOBI e BESEN, 2011).

A Política Nacional de Resíduos Sólidos, Lei n. 12.305 de 2010, no aspecto de sustentabilidade socioambiental urbana, cria mecanismos de inserção de organizações de catadores nos sistemas municipais de coleta seletiva e possibilita o fortalecimento das redes de organizações de catadores e a criação de centrais de estocagem e comercialização regionais (JACOBI e BESEN, 2011).

A formação de cooperativas de reciclagem em diversas regiões do Brasil tem sido objeto de investigação de pesquisas que mostram a importância dessa atividade para mitigar o impacto ambiental dos resíduos sólidos urbanos, por meio do trabalho de coleta seletiva de lixo. Por outro lado, estudos mostram as dificuldades desses profissionais que começam a se organizar em cooperativas, com o apoio, ainda precário, dos setores público e privado e da sociedade civil 
(SOUZA et al., 2012).

O Sistema de Gestão Ambiental (SGA) é um dos instrumentos para controlar e minimizar os impactos ambientais gerados dentro da organização, proporcionando melhorias nos custos da organização, racionalização dos insumos e matéria-prima utilizada nas atividades. Atualmente, o SGA é visto pelas empresas como um modo de lucrar e não um custo indesejável. Quando se adota um comportamento ambientalmente eficiente, se otimiza o uso dos recursos, evitando desperdícios na produção e possíveis custos como seguros, multas e outros.

Assim, este trabalho objetivou o levantamento dos aspectos/impactos ambientais de uma cooperativa de materiais recicláveis, bem como a proposição de medidas para a mitigação dos aspectos e impactos ambientais críticos.

\section{2 - METODOLOGIA}

Para a realização deste estudo, foi realizado um acompanhamento do processo produtivo, visando o conhecimento de todas as etapas do setor produtivo e a identificação dos resíduos gerados e do seu gerenciamento. Também, foram aplicados questionários junto aos cooperados para obter informações mais detalhadas a respeito da gestão ambiental existente.

Com esses dados foram identificados os aspectos e impactos ambientais do processo produtivo. Os impactos foram avaliados segundo a metodologia proposta por Moreira (2006), caracterizando-os quanto a sua natureza e relevância. A natureza do impacto foi classificada em positiva ou negativa em relação ao meio ambiente. A relevância avaliou a abrangência, a gravidade e a frequência do impacto. A abrangência analisou a extensão do dano, sendo classificada em pontual; local ou regional. Ao avaliar a gravidade do impacto, analisou a capacidade do meio ambiente em suportar ou reverter seus efeitos, classificando-a em baixa; média ou alta. E a frequência, que caracterizou a quantidade de vezes que o impacto ocorre, foi classificada em baixa; média ou alta. Ao final, obteve-se a significância, que é dada pela soma da abrangência, gravidade e frequência de tais impactos, podendo assim classificá-los em: desprezível; moderado; e crítico.

Após a avaliação dos aspectos e impactos ambientais foi possível à identificação dos impactos mais significativos gerados na cooperativa e com isso, definiram-se propostas visando à mitigação dos impactos. 


\section{3 - RESULTADOS}

Os processos realizados pela cooperativa estudada podem ser visualizados na Figura 1.

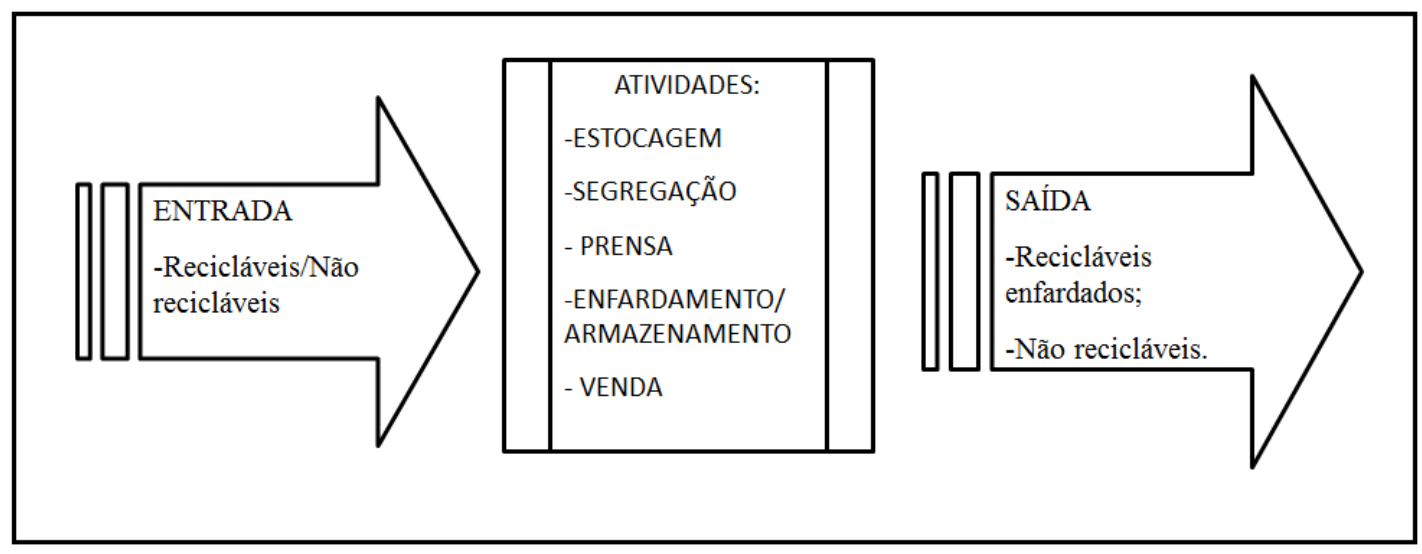

Figura 1. Fluxograma simplificado das atividades realizadas

Durante a realização do estudo, foram identificados 40 impactos, sendo $88 \%$ negativos e $12 \%$ positivos. Dos impactos negativos, $35 \%$ são críticos, $28 \%$ são moderados e $25 \%$ são desprezíveis, conforme pode ser observado na Figura 2.

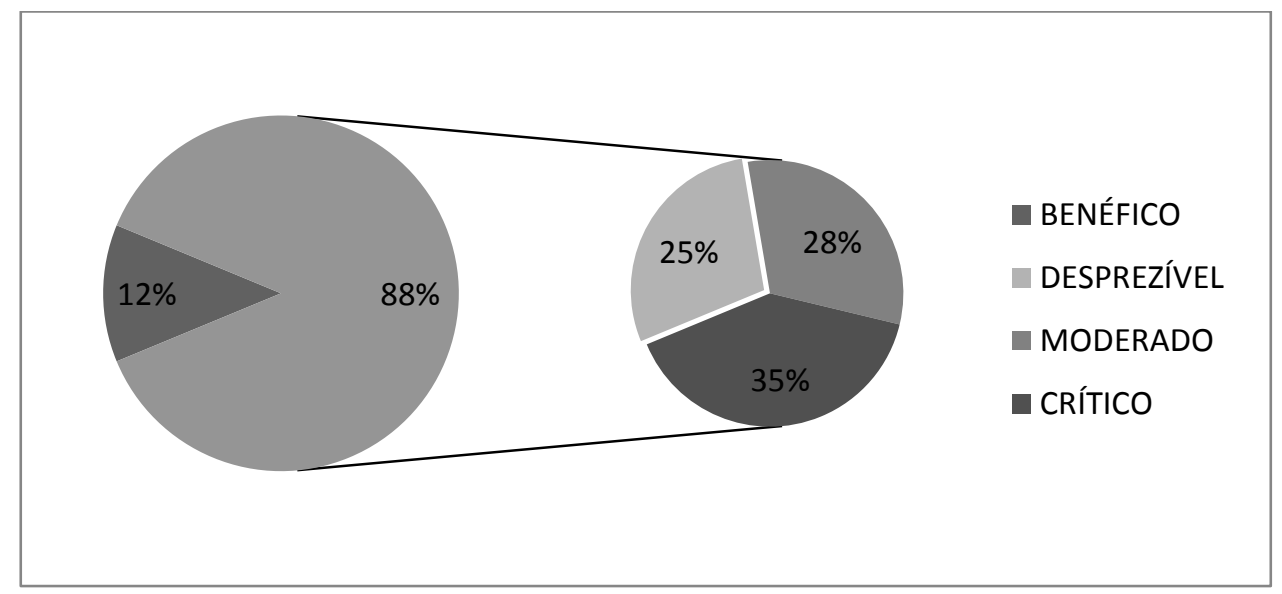

Figura 2. Porcentagem de impactos ambientais gerados na cooperativa

\section{4 - DISCUSSÃO}

Os processos realizados pela cooperativa começam a partir do recebimento da matériaprima (resíduos recicláveis e não recicláveis), seguido da estocagem dos resíduos, segregação dos resíduos, prensagem dos recicláveis, enfardamento/armazenamento e a venda.

A matéria-prima (resíduos recicláveis e não recicláveis) chega à cooperativa aproximadamente dez vezes por dia. Os caminhões são descarregados na frente do barracão e 
também numa área ao lado do barracão, diretamente no solo. Em função da grande quantidade de resíduos, os mesmos permanecem ali por dias até serem segregados.

O material sofre uma pré-segregação antes de ser levado para o barracão, pois muitas vezes são encaminhados para cooperativa, além dos resíduos recicláveis, alguns resíduos que não são aproveitados pela cooperativa como caixas de ovos e resíduos orgânicos.

Para que os resíduos estocados na área externa do barracão sejam processados, inicialmente os mesmos são encaminhados para um funil que os direciona para a esteira de separação, local onde ocorre manualmente a segregação dos resíduos pelos cooperados. São segregados plásticos (garrafas PET, embalagens PEAD como as de detergente, sacolas de supermercados, etc.); papel, papelão, jornal, revistas, cartões, etc.; vidro (embalagens de vidro, copos e utensílios de vidro em geral) e metal (latas de alumínio, outros).

Os resíduos de plástico e papel são prensados, embalados e armazenados dentro do barracão para posterior venda. O vidro e o metal são enfardados e armazenados, também no barracão, para posterior venda.

Junto com os resíduos recicláveis, também são encontrados resíduos orgânicos, aparelhos eletrônicos e outros rejeitos resultantes da segregação realizada na cooperativa. Os resíduos orgânicos são separados e destinados ao lixão do município.

Não há geração de efluente líquido durante os processos, somente é produzido esgoto doméstico nas áreas administrativas, banheiros e cozinha, destinado a uma fossa séptica.

Devido ao fato de que parte dos resíduos que chega à cooperativa é armazenada diretamente no solo, sofrendo ação de intempéries, há a produção de chorume no local e o surgimento de um odor característico.

Há emissão de ruído durante a prensagem. As atividades da cooperativa não emitem gases diretamente, mas há a circulação dos caminhões de coleta que liberam fuligem, gases prejudiciais à saúde e aumentam a concentração de poeiras na área.

Os aspectos positivos da cooperativa corresponderem a $12 \%$ dos impactos. Cerca de $60 \%$ dos impactos positivos estão relacionados com a melhoria da qualidade de vida e a melhoria no status social dos cooperados, estando relacionados ao aspectos geração de emprego e renda.

Os benefícios ambientais representaram $40 \%$ dos impactos positivos, indicados pelos aspectos segregação dos recicláveis dos não recicláveis e segregação entre os recicláveis. Estes aspectos geram dois impactos: diminuição dos recicláveis destinados ao aterro sanitário e redução 
de contaminações no meio ambiente. Além disso, também existem benefícios econômicos por meio da venda dos resíduos recicláveis, melhorando a qualidade de vida dos cooperados.

Os principais aspectos ambientais que causaram impactos desprezíveis foram: 10\% referente a geração de chorume; 30\% vazamento de contaminantes; $10 \%$ geração de ruído; $10 \%$ manuseio dos materiais prensados para enfardar; $10 \%$ armazenamento dos fardos no barracão; $30 \%$ armazenamento do óleo de cozinha usado.

Os aspectos manuseio dos materiais prensados para enfardar e o armazenamento dos fardos no barracão contribuem com $20 \%$ dos impactos desprezíveis. O primeiro aspecto citado pode causar danos à saúde do cooperado, que é considerado desprezível, pois nesta etapa os materiais já estão enfardados e a probabilidade de ocorrer algum acidente é menor. O segundo está relacionado com a geração de odor e a proliferação de vetores.

Os aspectos ambientais que causaram impactos moderados na cooperativa foram: $28 \%$ referente a estocagem (resíduos recicláveis/não recicláveis); 18\% consumo de energia; 9\% operação na esteira; $18 \%$ geração de resíduos sem valor comercial; $9 \%$ armazenamento dos fardos no barracão e $18 \%$ geração de esgoto doméstico. Dentre esses, o aspecto estocagem contribui com a maior porcentagem de impactos moderados, causando danos aos animais, poluição visual e alteração na qualidade dos materiais recicláveis.

Os aspectos ambientais que causaram impactos críticos foram: $28,57 \%$ referente à geração de chorume, 35,71\% estocagem de materiais perigosos, 28,57\% estocagem (resíduos recicláveis/não recicláveis) e 7,14\% do manuseio de materiais. Dentre os impactos referentes à geração de chorume estão as contaminações do solo, de corpos d'água e da água subterrânea, além da proliferação de vetores. A estocagem dos materiais perigosos, além de gerar a contaminação do solo, de corpos d'água, da água subterrânea, pode causar danos à saúde e danos à fauna e flora. O manuseio dos materiais gera o impacto crítico referente a danos à saúde e segurança do cooperado, já que eles possuem resistência na utilização de EPI's.

Como propostas para os aspectos ambientais que causaram impactos ambientais críticos na cooperativa, especificamente para a geração de chorume, estocagem dos materiais perigosos e estocagem de materiais, sugere-se a construção de uma área para proteger os resíduos das intempéries (radiação solar, chuvas, ventos, etc.) evitando a geração de chorume.

E quanto ao aspecto ambiental associado ao manuseio dos materiais, propõem-se a conscientização a partir de palestras. Também é necessário demonstrar a importância da utilização dos EPI's (luvas, calçados/botas e protetor auditivo) tornando-os obrigatórios, já que os 
cooperados apresentam resistência ao uso de EPI's nas atividades com risco à sua saúde e segurança; além de treinamento dos cooperados que realizam a prensagem dos materiais na prensa mecânica.`

\section{5 - CONCLUSÃO}

O estudo possibilitou o entendimento da diversidade dos impactos gerados numa cooperativa de materiais recicláveis.

Assim, destaca-se a atividade de estocagem a maior geradora de impactos críticos, junto com a falta de equipamentos de segurança e a contaminação dos recicláveis devido à vinda dos materiais sem higienização. Neste caso, as principais ações de melhoria envolvem a busca de incentivos públicos e privados para melhorar não somente a organização do barracão, mas a qualidade de vida dos cooperados, e a construção de um novo barracão, assim como a atração de novos cooperados para otimizar o trabalho.

\section{6 - REFERÊNCIAS}

JACOBI, P. R., BESEN, G. R. Gestão de resíduos sólidos em São Paulo: desafios da sustentabilidade. Revista Estudos Avançados. v. 25, n. 71, 2011.

MOREIRA, M. S. Estratégia e Implantação do Sistema de Gestão Ambiental (Modelo ISO 14000). 3. ed., Nova Lima: IDG Tecnologia e Serviços Ltda, 2006.

SOUZA, M. T. S., PAULA, M. B., SOUZA-PINTO, H. O papel das cooperativas de reciclagem nos canais reversos pós-consumo. Revista de Administração de Empresas. v. 52, n. 2, 2012.

\section{7 - AGRADECIMENTOS}

Os autores agradecem ao Programa Institucional de Bolsas de Iniciação Científica (PIBIC) da UNESP pelo apoio financeiro. 